« money for Evelina Children's Hospital. We are rehearsing every day and rehearsals are two hours each session. It's the passion for what we do that keeps us going.

Balancing dance and dentistry simultaneously can at times be very challenging, but I wouldn't have it any other way. Both are important in my life and I'm blessed to have opportunities to develop myself in these areas together.

I've also done some acting and modelling, but as a fourth year am focusing on dentistry at the moment. I'd love to continue pursuing performing arts if the opportunity arises after my graduation. Dance will always be a hobby for me, and I quite like the idea of being known as the 'dancing dentist' for the rest of my life!

When I do graduate from dental school, I'd like to spend the first few years working under

\section{CQC proposes reduced fees for dental practice}

The Faculty of General Dental Practice UK (FGDP[UK]) has welcomed a proposed 13.5\% reduction in the annual fees dental surgeries pay to the Care Quality Commission (CQC).

The CQC, which regulates health and social care providers in England - including over 10,000 dental practices - is moving to a system of setting fees on a full-cost-recovery basis, and has opened a consultation on its proposed fees for 2017/18. Should the proposals go ahead, every provider type other than dental surgeries would see an increase in fees.

In 2015 the CQC reported that over several years it had found that compared to other sectors, dental services present a lower risk to patients' safety, and reduced the number of practices it inspects to $10 \%$. It now anticipates that the costs it incurs in regulating dental practices will fall from $£ 8.4$ million in 2016/17 to $£ 7.3$ million in $2017 / 18$.

Fees paid by dentists already fully cover the CQC's dental costs, so under the new fee-setting arrangements the cost savings in inspecting the sector will be passed on to providers. By contrast, GPs currently pay only $57 \%$ of the costs of regulating GP surgeries, with the rest being picked up by the taxpayer.

The CQC's proposals are contained in its Regulatory Fees consultation document at: http://www.cqc.org.uk/sites/default/ files/20161020_fees-consultation-201718_ consultation-document.pdf. a well-established dentist and then take the plunge into the world of dental entrepreneurship and start my own practice, and in the process create an unrivalled environment to provide comprehensive, minimally invasive dental care, in a holistic fashion.

I normally get home around $11 \mathrm{pm}$, as I prefer staying in the library to get my work done, or I have dance rehearsals on. We actually have a purpose built dance studio in our house. About three years ago we demolished our shed and built a studio so my sister and I could choreograph and prepare for shows and competitions more effectively. We now only use this on the weekends, when the whole crew comes around for group drilling. I ensure I always make time for my loved ones and go out with friends and family regularly. It's worked out so well for me because most of my friends actually share a passion for dance.

When at home I usually unwind with a cup of hot tea and chat to my parents, filling them in on what's happened throughout my day. They're very loving and understanding, and constantly support my development.

I have lots of plans for 2017 and beyond. In January I will be leading a project which takes dental students into care homes to help residents and carers understand more about the role of diet and oral hygiene regimes in preventing and stabilising oral diseases. I also have more lectures planned and would like to visit schools to mentor youths about what dentistry is really like, and why I believe it's the best profession in the world. I have high hopes for the future for myself and my colleagues.

I usually get around six hours of sleep a night. Life is too exciting for sleep!

\title{
Workshop examines the 'fourth function' of the mouth
}

\section{Science Gallery London} has commissioned dentist and artist Kuang-Yi Ku to run a project on the 'fourth function of the mouth' [besides aesthetics, pronunciation, and mastication]: its involvement in sex.

\section{Ku's Fellatio}

Modification Project is part of Science Gallery London's autumn season 'Mouthy: into the orifice' which invites audiences to explore the hidden world inside the mouth.

The project focuses on medical and surgical oral modification practices for sexual pleasure enhancement, specifically for gay culture. To widen up the scope and reach of the project, Science Gallery London is organising a new Anilingus/Cunnilingus Modification workshop. King's College London dentistry students Carly Billing and Anisha Gupta extend Ku's experiments - use of saliva substitutes, tongue piercing, tongue splitting, prosthetic devices - to a wider range of sexual orientations and gender identities. They have created a prototype for a disposable wearable device to be used to increase sexual pleasure for women. They also want to raise awareness of effective protection methods for oral sex that do not prevent people from orgasm.

At a workshop which took place on 2 November, Ku led participants in creating oral sex toys based on dental retainers. At a talk held the same evening, $\mathrm{Ku}$, Gupta and Billing presented The Fellatio and Cunnilingus/Anilingus Modification Projects and facilitated discussion about the themes they leverage, including the limits of bodily transformation in the pursuit of better oral sex. 